\title{
A intertextualidade pós-moderna em Memorial do fim, de Haroldo Maranhão
}

\author{
Postmodern intertextuality in Memorial do Fim, by Haroldo Maranhão
}

\author{
Fabricio de Miranda FERREIRA* \\ Universidade Federal do Pará (UFPA)
}

RESUMO: Este artigo busca desenvolver reflexões sobre a intertextualidade presente em Memorial do fim, de Haroldo Maranhão, com a obra de Machado de Assis, evidenciando como esse diálogo intertextual resulta em um pastiche, em sua relação com o passado, características de uma literatura que denominamos pós-moderna. Para tanto, serão utilizados os conceitos de intertextualidade, trabalhado por Nitrini e Kristeva, de pós-moderno, trabalhado por Jameson e Miranda, e ainda o conceito de pastiche, por Jameson e, preferencialmente, por Hutcheon. Dessa forma, pretende-se lançar algumas considerações sobre o tema, para contribuir para o tema da intertextualidade na literatura contemporânea, dentro do contexto de um pós-modernismo na América latina. Percebe-se que a intertextualidade da obra de Haroldo Maranhão em relação a Machado de Assis se dá por uma estética que pode ser considerada pós-moderna, especificamente no aspecto da relação com o passado, ao reescrevê-lo por meio de um pastiche.

PALAVRAS-CHAVE: Intertextualidade. Pós-Moderno. Pastiche. Memorial do Fim.

ABSTRACT: This article seeks to develop reflections on the intertextuality present in Memorial do fim, by Haroldo Maranhão, with the work of Machado de Assis, showing how this intertextual dialogue results in a pastiche, in its relationship with the past, characteristics of a literature we call postmodern. To this end, we will use the concepts of intertextuality, worked by Nitrini and Kristeva, of postmodern, worked by Jameson and Miranda, and the concept of pastiche, by Jameson and, preferably, by Hutcheon. Thus, it is intended to launch some considerations on the theme, to contribute to the theme of intertextuality in contemporary literature, within the context of a postmodernism in Latin America. It can be seen that the

\footnotetext{
* Mestre em Letras - Estudos Literários do Programa de Pós-Graduação em Letras (PPGL/UFPA). Email: fmferreira815@gmail.com

Revista Moara, n. 53, ago-dez 2019 ISSN: 0104-0944 
intertextuality of Haroldo Maranhão's work in relation to Machado de Assis is due to an aesthetic that can be considered postmodern, specifically in the aspect of the relationship with the past, when rewriting it through a pastiche.

KEYWORDS: Intertextuality; Postmodern; Pastiche; Memorial do Fim.

\section{Introdução}

Haroldo Maranhão (1927-2004) esteve no epicentro de acontecimentos históricos e literários desde muito cedo. Nascido em uma família de jornalistas, e, isolado no prédio do jornal da família durante a infância, devido à perseguição política, desde cedo vivenciou a agitação política e cultural da capital paraense. A própria história de Belém iria ocupar muito de seus livros, servindo de inspiração para suas obras.

Com a criação do suplemento literário Arte-Literatura, do Jornal Folha do Norte, Haroldo Maranhão contribuiu significativamente para a literatura do país, ao propiciar a adesão dos escritores e intelectuais paraenses aos suplementos literários que se espalhavam pelo Brasil. Nesse suplemento colaboraram os maiores literatos e intelectuais da época, não só do Pará, mas do Brasil. Além do suplemento, Haroldo Maranhão, juntamente com Mário Faustino e Benedito Nunes, dirigiu a revista literária Encontro, que possuía a mesma premissa do suplemento.

Importante frisar que, embora desde cedo estivesse cercado de livros e autores consagrados, sua estreia como escritor se deu apenas em 1968, aos 41 anos. Seu melhor momento, porém, viria na década de 1980 e início dos anos 1990, portanto, já distante do modernismo com o qual conviveu nos tempos do suplemento. Naquele período, a literatura brasileira já superara os paradigmas do modernismo e do regionalismo, vivendo uma época marcada por uma pluralidade que iria caracterizar a literatura até hoje, considerada por muitos como pós-modernista.

Memorial do fim (1991), obra sobre a qual se debruça este artigo, foi uma das últimas obras do autor paraense. Nela, o próprio Haroldo admite que se trata de uma homenagem à Machado de Assis, que dispensa apresentações. O maior escritor 
brasileiro de todos os tempos foi um amor antigo do paraense, como afirma o autor no Post Scriptum do livro: "Este romance resultou de um amor que remonta à minha adolescência” (2004, p. 197). Uma sinopse bastante reducionista, que jamais daria conta da complexidade do livro, diria que tal homenagem consiste em reconstituir os últimos dias de vida de Machado, por meio de um pastiche/paródia da obra machadiana, estabelecendo um diálogo intertextual óbvio não somente com a obra, mas com a biografia do grande escritor carioca.

Este artigo objetiva desenvolver reflexões sobre essa intertextualidade presente em Memorial do fim com a obra de Machado de Assis e como esse diálogo intertextual resulta em um pastiche, em sua relação com o passado, características de uma literatura que se denomina pós-moderna.

Para tanto, serão utilizados os conceitos de intertextualidade, trabalhado por Nitrini e Kristeva, de pós-moderno, trabalhado por Jameson e Wander Melo Miranda, e ainda o conceito de pastiche, por Jameson e de paródia, por Linda Hutcheon. Pretendese fazer uma breve reflexão, com o objetivo de lançar algumas considerações sobre o tema, à guisa de estabelecer uma relação entre a intertextualidade e a literatura pósmodernista.

\section{Um olhar pós-moderno para o passado}

A partir da segunda metade do século $\mathrm{XX}$, mudanças históricas viriam a ocasionar alterações no modo de se pensar a sociedade, suas instituições e manifestações culturais. Naquele momento, conforme Jameson (2002), houve uma ruptura na arte, após, segundo as palavras do autor, a "canonização e institucionalização acadêmica do movimento moderno" (2004, p. 30). Para ele, essa é uma das explicações mais plausíveis para o aparecimento do pós-modernismo, uma vez que a geração de 60 vai se confrontar com o movimento moderno, iniciando uma série de mudanças que dariam luz ao novo fenômeno a ser estudado e nominado.

A pós-modernidade não tem uma conceituação fácil, mas pode-se resumir suas características mais importantes: o homem não tem mais uma identidade fixa, cujo centro é a sua personalidade única (HALL, 2003); a incredulidade em relação às 
próprias metanarrativas, como saberes únicos e totalizantes (LYOTARD, 2002); a valorização de uma multiplicidade de estilos ao invés da originalidade modernista; uma reescritura do passado, estabelecendo uma ponte, diferente do modernismo, que via o passado como algo a ser superado.

Por todas essas mudanças, pode-se dizer, como muitos críticos, que a pósmodernidade não é um conceito com uma definição certa, mas é inegável que há uma grande transformação, ainda em curso, muito mais rica em perguntas do que certezas, que se reflete em várias realizações artísticas e culturais, entre elas, a literatura.

Mais uma controvérsia na conta do pós-moderno: seria apropriada a aplicação do termo à realidade dos chamados países de terceiro mundo, onde está incluída a América latina e o próprio Brasil? Alguns dos principais estudiosos do tema já divergiram quanto a isso. No que se refere às relações entre o pós-moderno e a América Latina, Nestor Garcia Canclini se refere à hibridização cultural existente nesse continente como algo fundamental no pós-modernismo. Quanto ao desenvolvimento, Canclini observa a heterogeneidade latino-americana referente aos estágios de cada país:

Hoje concebemos a América Latina como uma articulação mais complexa de tradições e modernidades (diversas, desiguais), um continente heterogêneo formado por países onde, em cada um, coexistem múltiplas lógicas de desenvolvimento. Para repensar esta heterogeneidade é útil a reflexão antievolucionista do pós-modernismo, mais radical que qualquer outra anterior (CANCLINI, 1990, p. 28).

Percebe-se desta forma que Canclini estabelece uma relação entre o pósmoderno e a multiplicidade cultural e de estágios de desenvolvimento da América Latina. Essa mistura singular dos países latinos, conforme Canclini, é algo que está bastante ligado à proposta pós-moderna.

Multiplicidade que, por sinal, tem marcado a literatura brasileira nas últimas décadas. No campo artístico em geral, a contemporaneidade tem presenciado fortes mudanças que envolvem estilos variados e multiformes, procedimentos de vanguarda, posicionamentos divergentes, aproximação das culturas erudita e popular, reescritura do passado. Em todas essas mudanças o que é certo é que há, sem dúvida, traços da pósmodernidade. Justifica-se, então, falarmos em Pós-modernismo na literatura e na cultura brasileira (ARRUDA, 2005).

Revista Moara, n. 53, ago-dez 2019 ISSN: 0104-0944 
Wander Melo Miranda (1996) materializa a controvérsia em torno do conceito de pós-modernidade ao indagar a utilização do prefixo pós, uma vez que denota algo depois, como se fosse uma superação ou um estágio posterior à modernidade, embora esta mesma, em si, já traga o sentido de ruptura, de incessante renovação, de plural que o pós-moderno advoga para si: "Os dogmas do progresso e da inovação não se veriam reafirmados nessa palavra de ordem contra a modernidade?" Para tentar desfazer essas dúvidas, Miranda sugere que o prefixo pós não indica uma simples contradição ao que ficou para trás, não supõe a ideia de uma progressão linear do tempo e da história, mas antes "o pós-moderno é, segundo Lyotard, um trabalho de perlaboração da modernidade, um ato de convalescença das enfermidades do moderno" (1996, p. 15). O pós-moderno só teria sentido, portanto, enquanto reescrita da modernidade, levada a efeito a partir de um ato de escuta do passado, que, ao invés de repeti-lo, busca realizar uma pontuação capaz de infiltrar-se no seu tecido de significantes, reorganizando-o por meio de uma atenção flutuante que torne possível o acesso ao desejo de modernidade:

Não se trata de resgatar fatos em estado bruto, mas de desconstruir, recriando, as redes significantes de conteúdos recalcados, os pontos de resistência em cima dos quais se processa a perlaboração, trabalho sem fim nem finalidade preconcebida (MIRANDA, 1996, p. 15)

Portanto, a pós-modernidade possui uma relação bastante diferente da que o modernismo possuía com o passado: se o modernismo voltava-se contra o passado, vendo-o como tradições a serem superadas, o pós-modernismo vai se voltar para o passado, reescrevendo-o, reorganizando-o e ressignificando-o.

Lyotard defende que existe uma condição pós-moderna que decretou o fim das narrativas mestras e totalizantes - entre elas a história, na acepção do pensamento marxista, como narrativa linear e centrada. Nesse aspecto, a literatura, dentro do contexto da arte em geral, estaria vivenciando, na contemporaneidade, uma estética marcada pela fragmentação, intertextualidade e pastiche. Tal fragmentação reflete em uma mistura de gêneros e mesmo modelos literários, mas também com outras artes, como a música e o cinema, promovendo a mistura estilística que favorece o ecletismo e a junção de códigos. Finalmente, o novo parece não existir, o que existe é apenas o 
"reaproveitamento", a "releitura", a "adaptação" do passado, ou ainda, a mistura de momentos históricos, de linguagens, culturas e estilos de época (COSTA, 2012).

\section{Quem conta um conto aumenta um ponto: a intertextualidade pós- moderna}

Segundo Nitrini (2010), o conceito de intertextualidade surgiu dentro do contexto de renovação dos estudos de literatura comparada, a partir da segunda metade do século XX. Concebida por Julia Kristeva, foi recebida por muitos comparatistas como um instrumento capaz de injetar sangue novo no estudo dos tradicionais conceitos de "fonte" e "influência", tão caros à literatura comparada. Segundo Kristeva apud Nitrini "todo texto se constroi como um mosaico de citações, todo texto é absorção e transformação de outro texto" (2010, p. 161). Nesse sentido, a noção de texto em Kristeva é ampla, tornando-se em "sistema de signos", quer se trate de obras literárias, de linguagens orais, de sistemas simbólicos, sociais ou inconscientes. Para evitar uma interpretação redutora do conceito, diz a autora:

\footnotetext{
O termo intertextualidade designa esta transposição de um ou vários sistemas de signos num outro, mas já que este termo foi frequentemente entendido no sentido banal de 'crítica de fontes' de um texto, preferimos o de "transposição" que tem a vantagem de precisar que a passagem de um sistema significante a um outro exige uma nova articulação da temática existencial, da posição enunciativa e denotativa (KRISTEVA, 2005, p. 60)
}

Nesse sentido, a intertextualidade estaria presente em todos os textos literários, não somente naqueles em que essa característica fica mais evidente. No entanto, cabe observar que o surgimento do conceito de intertextualidade surgiu na segunda metade do século XX, coincindindo com a efervescência cultural que envolveu o pósmodernismo, dentro de um contexto da visão desconstrutivista, marcada, entre outras ideias, pela morte do sujeito (NITRINI, 2010). Nesse sentido, a ideia de intertextualidade, ao opor-se ao antigo conceito de influência, derruba a ideia de modelos a serem seguidos, inserindo a literatura em um contexto de sistema amplo de 
signos, marcado pela troca constante, onde a questão da propriedade e da originalidade se relativizam e a questão da verdade se torna impertinente.

Para esclarecer esse paralelo entre a intertextualidade e o pós-modernismo, recorramos mais uma vez a Jameson (2002). O teórico americano relaciona as mudanças sociais, políticas e econômicas na pós-modernidade e seus reflexos nas artes, e consequentemente nas letras. $\mathrm{Na}$ arte pós-moderna a ideia da autoria estaria comprometida, uma vez que se perdeu o espírito intuitivo de criação, de originalidade criada lá atrás, pelos românticos. O que há na arte contemporânea, conforme Jameson (2002), é a retomada da écriture dos grandes imortais canonizados pela crítica literária. Estaria, de fato, extinto o autor-presença na arte contemporânea. O "desaparecimento do sujeito" criador, autônomo, tornando o discurso impessoal, contribuirá para a formação do pastiche na cultura contemporânea como um recurso estético exemplar.

Como prática intertextual, o pastiche está ligado intrinsecamente à temporalidade na cultura contemporânea. Assim, se o sujeito perdeu seu espaço na criação artística neste contexto, o que lhe resta é fazer pastiche dos grandes estilos (SALES, 2007, p. 161).

É preciso salientar, conforme Sales (2007), que Jameson utiliza o termo pastiche de forma pejorativa. Contribuindo para a discussão, Hutcheon (1991) tem outro posicionamento. A crítica literária canadense prefere o termo paródia, uma vez que, segundo ela, não interessa aos pós-modernos fazer releituras que privilegiam o desvio crítico, e sim, representar esteticamente as semelhanças entre os textos que dialogam com outros textos. Por meio da comparação entre texto base e texto parodiado, então, as semelhanças apontam ainda mais para as diferenças peculiares do texto final.

Portanto, tanto o termo pastiche como o termo paródia apontam para o recurso estético de retomada de estilos anteriores, seja aproveitando-os em forma de colagem, seja em forma de homenagem. Como veremos a seguir, percebe-se no romance em estudo as duas formas: tanto a colagem de características únicas do estilo de Machado de Assis, como a ausência de um desvio crítico, mas sim de uma homenagem ao escritor carioca.

Portanto, adotou-se nesta pesquisa o termo pastiche, mas procurando desviar-se da conotação pejorativa de Jameson, adotando, nesse sentido a contribuição do conceito 
de paródia de Hutcheon. Tal conceito será aplicado para verificar as relações intertextuais que o romance de Haroldo Maranhão, estabelece em relação à obra de Machado de Assis, por meio do pastiche, caracterizando, assim, como uma obra com características pós-modernas.

\section{Memorial do Fim: mais que um pastiche, uma narrativa pós- moderna}

Memorial do fim - A morte de Machado de Assis foi publicado em $1991 \mathrm{e}$ chamou atenção na época por reconstituir os últimos dias do maior escritor brasileiro de todos os tempos, obtendo um lugar de destaque entre os romances contemporâneos. O romance é muito mais do que uma recriação histórica de uma vida e de uma época. Movido pela profunda admiração que nutria pelo escritor carioca, o paraense mergulhou no universo machadiano de forma a assimilar, na própria escrita, o seu estilo. $\mathrm{O}$ resultado mistura a tal ponto ficção e história que se torna impossível saber onde termina uma e começa outra; o narrador é, ao mesmo tempo, o autor de Dom Casmurro e o conselheiro que protagoniza Memorial de Aires, último romance publicado por Machado.

Assim, aos últimos dias de Machado são acrescidos fatos reais que se passaram no ano de 1908, mais especificamente, entre os meses de abril a setembro. São inseridas no enredo personalidades históricas, como por exemplo, José Veríssimo, Euclides da Cunha, Joaquim Nabuco, Olavo Bilac, Barão do Rio Branco, além de pessoas do convívio com Machado de Assis naqueles tempos, como a criada Jovita Maria de Araújo e Leonora, que ora se apresenta como Marcela ou Hylda, além de outras personagens que vão aparecendo no romance à medida que o enredo avança, se aproximando do fim de sua vida.

Mas, como já se pode perceber, o escritor paraense não fica apenas na reconstituição puramente histórica: o enredo ainda absorve fragmentos da obra de Machado de Assis em forma de capítulos que são justapostos de forma a criar uma nova história, dentro de um novo contexto, possibilitando um enredo fragmentado e complexo. O romance se constrói a partir de relações intertextuais formadas por trechos 
inteiros de obras machadianas (devidamente editados por Haroldo), transcrição de cartas, de páginas de diário, de panfletos publicitários e de vários textos que resgatam a memória e a vida pessoal de Machado. Nesse sentido, o romance Memorial do fim é considerado como exemplo de narrativa que promove ficcionalização da ficção e da história brasileira na contemporaneidade.

$\mathrm{O}$ período histórico recriado no romance é o início do século $\mathrm{XX}$, mais especificamente, o ano de 1908, servindo como contexto da morte real de Machado. Mas isso não quer dizer que outros períodos não sejam aproveitados, pelo contrário, a obra vai promover várias idas e vindas no tempo, em um enredo não linear. O capítulo $\mathrm{XV}$, "Um evento de 1876", representa um momento bem anterior ao da narrativa, sem deixar de problematizar a relação autor-leitor, uma característica eminentemente machadiana:

\footnotetext{
Convido o leitor a retomar comigo ao ano de 1876; que lhe estará senão acompanhar-me, sujeitando-se à minha onipotência, que efetua guinadas finas e volteios movidos à ação do capricho? $\mathrm{O}$ autor manda; o leitor, se for bom, sujeita-se. Tirano? Quem fez a sensata indagação? Tirano. Não estaria aqui quem lhe negasse razão. Naquele ano, um negociante atilado inventou modas: bengalas para meninos! Ora, ora, bengalas para meninos! [...] São finas cousas. Então, que diabo de ideia meteu-se-lhe na cabeça, mais cabaça, do negociante de 1876? Ideias de canário sem ideias. (MARANHÃO, 2004, p. $57-58)$
}

Importante que se diga que o romance, inclusive nesse trecho citado, não se refere a acontecimentos grandiosos ou de grande importância histórica, como era comum ao romance histórico em seu apogeu, do século XIX, que vai de Walter Scott a Tolstoi - ao invés disso, proporciona uma reflexão do próprio fazer literário e da morte - tema caro à obra de Haroldo - em meio a acontecimentos comuns da vida de um escritor canônico, humanizando-o e simultaneamente, exaltando sua grandeza, mesmo como moribundo.

Concomitante a isso, a inserção de personagens machadianos no enredo não se dá de forma aleatória. Segundo Sales (2013) a convivência de personagens que transitam no enredo de Memorial do fim produz novos quadros que se apoiam em outros, devido aos mecanismos de espelhamentos entre elas e da (não) distinção entre realidade e ficção. Personagens machadianas como D. Carmo, Fidélia, Marcela 
(Vanlogo), e as reais como Leonora (Hylda), D. Carolina, Jovita Maria de Araújo, Perpétua Penha Nolasco, dentre outras de menor importância no enredo, são peças fundamentais do "jogo de xadrez”, já que, na troca de nomes e de papéis, a movimentação que cada personagem executa é estratégica dentro dos princípios que regem o tabuleiro (SALES, 2013). Além disso, as personagens femininas ganham destaque na trama, como uma homenagem às mulheres de Machado.

Em mais um diferencial do romance de Haroldo, Memorial do fim vai além de uma recriação histórica ao fazer conviver personagens fictícios e reais, de forma a, em determinados momentos, trocá-los de posição, como se fossem peças de um jogo, como se fosse um sonho ou um delírio de um narrador inconstante, sendo que a própria identidade do narrador sofre variação (ora é Machado, ora é o Conselheiro Aires). Dessa forma, Haroldo se utiliza de um modelo realista (Machado) para criar uma obra que rompe com o próprio realismo.

Em um outro aspecto importante, o romance tem características do pósmodernismo, ao se inserir no rol de obras intensamente autorreflexivas e paródicas e, ainda assim, procurando firmar-se naquilo que aparentemente constitui um entrave para a reflexividade e a paródia: o contexto histórico. Essa nova prática paródica (aqui neste artigo relacionada ao pastiche de Haroldo) busca inserir os intertextos históricos e literários empregando como principal estratégia retórica a ironia. Conforme Hutcheon, “a paródia pós-moderna, através da ironia, assinala a distinção em relação ao passado, mas a imitação intertextual, ao mesmo tempo, atua no sentido de afirmar - textual e hermeneuticamente - o vínculo com o passado" (HUTCHEON, 1991, p. 164).

Nesse sentido, podemos afirmar que o romance de Haroldo Maranhão utiliza dessa prática paródica, como uma das principais características da narrativa pósmoderna. Ou seja, a intertextualidade do pastiche aqui não é aleatória e sem sentido, mas expõe os fatos do passado reelaborados no romance, conforme se pode perceber na recriação das visitas históricas ao notável escritor à beira da morte. Assim, Machado irá receber as várias visitas, alternando sua imagem retratada ora como o sublime escritor em sua aura, tendo em seu entorno as celebridades da época, ora como miserável moribundo convivendo com personagens fictícios (seus fantasmas?). Essa fragmentação da identidade é uma das premissas básicas da narrativa pós-moderna: a perspectiva sem 
foco, descentralizada, na caracterização dos personagens. Tal estratégia irá se repetir ao longo do romance no espelhamento de um personagem no outro - Machado alternará entre o Conselheiro Aires, Aguiar, e ainda, Brás Cubas, o protagonista das Memórias Póstumas. Tal estratégia também será adotada na multiplicidade de narradores: Brás Cubas / Conselheiro Aires / Machado. Outra fragmentação se dará na imagem de Machado, ora endeusada: "O nosso morto era excelso, amado, quisto, benigno" (MARANHÃO, 2004, p. 127); ora causará asco e repugnância em sua decrepitude física, como transparece nos comentários do Barão do Rio Branco (personagem histórico cuja visita foi recriada ficcionalmente no romance): "Mas este homem! Apodrece! Fede! E insiste!” (MARANHÃO, 2004, p. 40).

Finalmente, percebe-se que a intertextualidade de memorial do fim em relação a Machado se dá por uma estética assumidamente pós-moderna, tanto em sua relação com o passado, ao reescrever esse passado por meio de um pastiche, um reaproveitamento do estilo consagrado machadiano, colando trechos de um grande autor em forma de homenagem, permitindo um novo significado, aproximando-se assim da paródia que propõe Hutcheon como sendo uma característica eminentemente pós-moderna; como em seu aspecto fragmentário, desenvolvendo uma narrativa pródiga em digressões e com personagens que mudam constantemente de lugar em um jogo complexo de significações.

\section{Considerações finais}

Importante resgatar as palavras do próprio Haroldo Maranhão, no Post scriptum, última parte do livro em que o autor traz explicações sobre a história:

\footnotetext{
O romance é pretensioso no pior sentido, sou o primeiro a admitir, antes que me passem a frente. Orientou-se pela tenaz ambição de honrar a narrativa machadiana, o andamento hesitante, certas soluções que são dele só, de mais ninguém. A mal arranjada imitação, ou pastiche, vagamente lembrará o original - inimitável - na media em que a música da flauta lembra a do violão (MARANHÃO, 2004, p. 199)
}

Importante observar como o autor utiliza a expressão pastiche para caracterizar sua obra, ao mesmo tempo em que afirma que a intenção é honrar a obra de Machado. E 
vai além, chamando-a de "mal arranjada imitação", consciente de que sua escrita jamais conseguirá imitar plenamente a obra clássica machadiana.

Isso nos leva a ver o quanto Haroldo era consciente da intertextualidade pasticheira que estabeleceu com Machado, assumindo tal relação como uma homenagem. Tal postura por si só já difere veementemente da postura modernista, que primava pela originalidade e contestação do passado, superação de tudo que fosse tradição. Haroldo, em toda sua obra, vai utilizar constantemente essa postura com o passado: sua obra vai buscar tanto inspiração no longínquo quinhentismo, como na prosa de Guimarães Rosa, proporcionando um estilo que se caracteriza pela multiplicidade referencial.

No entanto, o que torna Haroldo Maranhão digno de destaque no cenário da literatura contemporânea? Justamente aquilo que nos faz, no contexto latino-americano, nas palavras de Miranda, ser modernos, sendo pós-modernos (1996): a reescrita da modernidade. Como vimos, o pós-moderno é, segundo Lyotard, citado por Miranda, um trabalho de perlaboração da modernidade, um ato de convalescença das enfermidades do moderno. O pós-moderno só teria sentido, portanto, enquanto reescrita da modernidade, levada a efeito a partir de um ato de escuta do passado. E, talvez aí resida a importância da obra de Haroldo: uma reescrita do passado, proporcionando um novo sistema de significado, onde a multiplicidade pode abrir importantes vias de interpretação da história.

\section{Referências}

ARRUDA, A. M. de. Cultura e literatura contemporâneas: algumas abordagens do pósmoderno. Estação Literária Londrina, v. 9, p. 220-237, 2012.

CANCLINI, Néstor García. La modernidad después de la posmodernidad. In:

BELUZZO, Ana Maria de Moraes (Org.). Modernidade: vanguardas artísticas na América Latina. São Paulo: UNESP, 1990

COSTA, J. Pós-modernidade, cultura e pastiche: algumas considerações acerca da contemporaneidade. In: Seminário Linguagem e Identidades: múltiplos olhares, 3, 2012, São Luiz: UFMA. Disponível em: http://www.linguagemidentidades.ufma.br/ 
publicacoes/pdf/Artigo\%20Janete\%20de\%20Jesus\%20Serra\%20costa.pdf. Acesso em: 25 nov. 2016.

HALL, S. A identidade cultural na Pós-Modernidade.7. ed. Rio de Janeiro: DP\&A Editora, 2003.

HUTCHEON, Linda. Poética do pós-modernismo: história, teoria, ficção. Tradução de R. Cruz. Rio de Janeiro: Imago, 1991.

JAMESON, F. Pós-Modernismo: A lógica cultural do capitalismo tardio. 2. ed. São Paulo: Editora Ática, 2002.

KRISTEVA, J. Introdução à semanálise. Tradução de Lúcia Helena França Ferraz. 2. ed. São Paulo: Perspectiva, 2005.

LYOTARD, J-F. A Condição Pós-Moderna. $7^{\text {a }}$ edição. Rio de Janeiro: José Olympio Editora, 2002.

MARANHÃO, H. Memorial do fim - A morte de Machado de Assis. São Paulo: Marco Zero, 2004.

MIRANDA, W. M. Pós-modernidade e tradição cultural. In: CARVALHAL, T. F (org.). O discurso crítico na América latina. Porto Alegre: Editora Unisinos, 1996.

NITRINI, Sandra. Literatura Comparada. São Paulo: EDUSP, 2010.

SALES, P. A. Haroldo Maranhão e a ficcionalização do cânone no romance brasileiro contemporâneo. In: Simpósio Nacional e Internacional de Letras e Linguística, v. 3, n. 1, 2013, Uberlândia: EDUFU. Disponível em: http://www.ileel.ufu.br/anaisdosilel/pt/arquivos/gt_lt16_artigo_4.pdf. Acesso em: 25 nov. 2016.

SALES, P. A. Para (além da) ode: o pastiche em memorial do fim. ÍCONE - Revista de Letras, São Luís de Montes Belos, v. 1, p. 154-172, 2007. 